\title{
RETRACTION
}

NOTE

\section{Retraction Note to: Synthesis of Biologically Active Nickelocenyl-Amino Acid Conjugates Using 1,3-Dipolar Cycloaddition Click Reactions}

\author{
M. A. $\operatorname{Raza}^{a}$, M. Amin ${ }^{a}$, G. Muhammad ${ }^{a}$, A. Rashid ${ }^{a}$, and A. Adnan ${ }^{a, *}$ \\ ${ }^{a}$ Department of Chemistry, GC University, Katchery Road, Lahore, Punjab, 54000 Pakistan \\ *e-mail:ahmadadnan@gcu.edu.pk
}

Received December 18, 2020; revised March 24, 2021; accepted March 26, 2021

DOI: $10.1134 / \mathrm{S} 1070363221040290$

The editor-in-chief of Russian Journal of General Chemistry has retracted this article [1], because the conclusions of this work are based on findings of article [2] that has been retracted earlier because of unreliable data presented there. This fact overturns findings of article [1]. The authors were notified of the decision of the editor-in-chief and disagreed with it, but did not provide convincing arguments against this decision.

\section{REFERENCES}

1. Raza, M.A., Amin, M., Muhammad, G., Rashid, A., and Adnan, A., Synthesis of Biologically Active Nickelocenyl-Amino Acid Conjugates Using 1,3-Dipolar Cycloaddition Click Reactions, Russian Journal of General Chemistry, 2017, vol. 87, no. 11 , pp. $2678-2683$.

https://doi.org/10.1134/S107036321711024X

2. Raza, M. A., Pervaiz, M., Rashid, A., Mustafa, H., Adnan, A., Synthesis, Characterization and Biological Studies of Ethynyl Nickelocene, Asian J. Chem., 2016, vol. 28, no. 5, pp. 947-953. 